\title{
Follicular thyroid cancer with functioning lung metastasis
}

Queenie Ngalob, MD, Ruben Ogbac, MD, Myrna Buenaluz-Sedurante, MD Section of Endocrinology, Diabetes and Metabolism

Department of Medicine

University of the Philippines - Philippine General Hospital

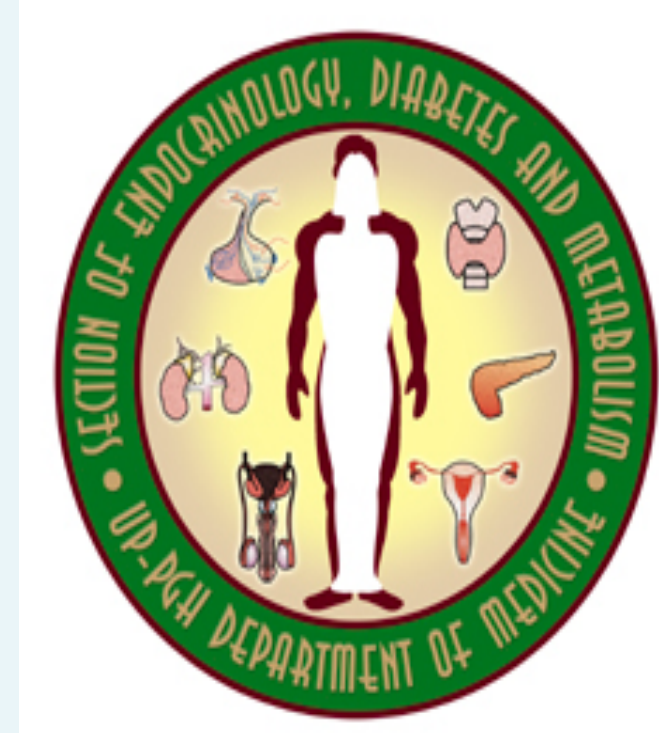

\section{SYNOPSIS}

- Functioning metastasis from a primary thyroid cancer is rare.

- Failure to proceed to hypothyroidism after total thyroidectomy denotes remaining hormone production from functioning metastasis if the thyroid remnant is small.

-We present the case of a patient with follicular thyroid cancer, lung metastasis and detectable thyroid hormones after thyroidectomy

\section{CLINICAL PRESENTATION}

\section{- 71 year old Filipina}

- 3 prior thyroid surgeries for recurrent multinodular goiter

- 1990 - lost to follow-up, histopathology unknown

- 1998 - s/p excision, again lost to follow-up

- 2001-s/p excision; Histopathology : Follicular carcinoma, lost to follow-up, no RAI

- $1 \frac{1}{2}$ yrs prior to consult, recurrence of thyroid nodules, no obstructive/thyrotoxic symptoms

- Two distinct adjacent masses on the anterior neck

- $6 \times 6 \mathrm{~cm}$ and $4 \times 4 \mathrm{~cm}$

- doughy and fixed to the neck

- $1 \times 1 \mathrm{~cm}$ lymph node along the inner border of the right sternocleidomastoid

\begin{tabular}{|l|c|c|}
\hline \multicolumn{3}{|c|}{ PREOPERATIVE WORK-UP } \\
\hline & Patient & Normal values \\
\hline TSH & $0.03 \mathrm{mIU} / \mathrm{L}$ & $0.3-3.8$ \\
\hline FT4 & $46 \mathrm{pmol} / \mathrm{L}$ & $11-24$ \\
\hline FNAB & Follicular Neoplasm & \\
\hline & & \\
\hline
\end{tabular}

1. Thyroid scintigraphy shows confluent functioning thyroid tissues in the left thyroid bed; 2 . CT scan (axial view) of the neck. Left thyroid lobe (L) converted into a large solid mass with central necrosis \& rightward tracheal (T) deviation; metastasis.

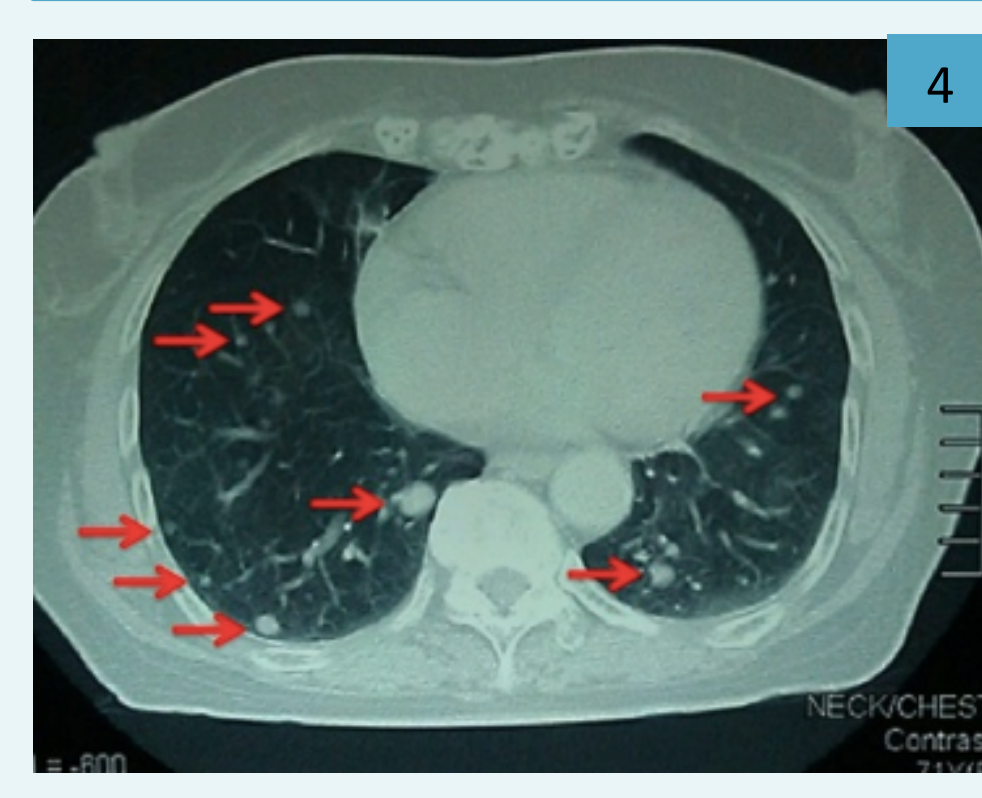

3. CT scan (coronal view)-
heterogeneously enhancing left
thyroid mass ( $M$ deviating the
trachea $(T)$ contralaterally and with
Intrathoracic extension(star); 4 . CT
scan (axial view) of the lower lung
lobes- multiple nodules red arrows),
consistent with metastasis.

INITIAL TREATMENT AND OUTCOME

- Normal FT4 after 4 weeks of Methimazole 20 mg daily

- Underwent completion thyroidectomy with lymph node dissection

Final histopathologic diagnosis:

- Recurrent Follicular thyroid cancer with lymph nodes and pulmonary metastasis, St. IVC

- Autonomously functioning thyroid nodules

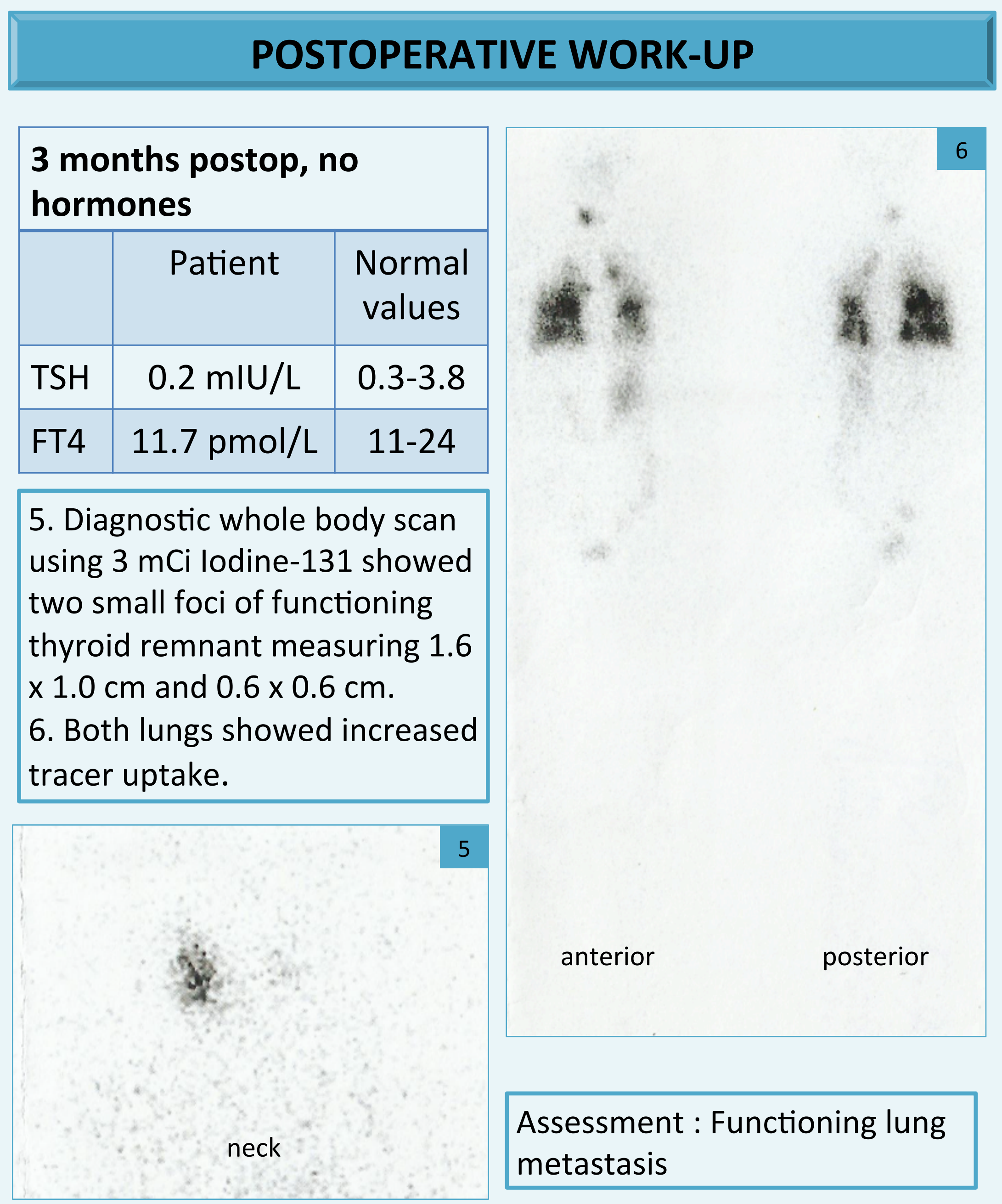

\section{SUBSEQUENT TREATMENT AND OUTCOME}

The patient underwent radioactive iodine-131 ablation (RAI) therapy with $150 \mathrm{mCi}(5.55 \mathrm{GBq})$. Hypothyroidism was demonstrated 1 month after RAI.

\begin{tabular}{|c|c|c|}
\hline & Patient & $\begin{array}{c}\text { Normal } \\
\text { values }\end{array}$ \\
\hline TSH & $33.4 \mathrm{mlU} / \mathrm{L}$ & $0.3-3.8$ \\
\hline FT4 & $8.2 \mathrm{pmol} / \mathrm{L}$ & $11-24$ \\
\hline
\end{tabular}

\section{CONCLUSION}

- Radioactive iodine ablation (RAI) is the treatment for functioning lung metastasis.

- RAl can be done even with a suppressed thyroid stimulating hormone (TSH) since functioning metastasis will uptake I-131.

- Postablative hypothyroidism denotes successful eradication of functioning metastasis. 